\title{
Robust Identification for Fault Detection and Diagnosis of Hydraulic Servo Cylinder
}

\author{
Vladimir Stojanović ${ }^{1)}$ \\ Dragan Pršicí ${ }^{1)}$
}

\begin{abstract}
Intensive research in the field of mathematical modeling of hydraulic servo systems has shown that their mathematical models have many important details which cannot be included in the model. Due to impossibility of direct measurement or calculation of dimensions of certain components, leakage coefficients or friction coefficients, it was supposed that parameters of the hydraulic servo system are random (stochastic nature). On the other side, it has been well known that the hydraulic servo cylinder can be approximated by a linear model with time-varying parameters. An estimation of states and time-varying parameters of linear state space models is of practical importance for fault diagnosis and fault tolerant control. Previous works on this topic consider estimation in Gaussian noise environment, but not in the presence of outliers. The known fact is that the measurements have inconsistent observations with the largest part of the observation population (outliers). They can significantly make worse the properties of linearly recursive algorithms which are designed to work in the presence of Gaussian noises. This paper proposes the strategy of parameter-state robust estimation of linear state space models in presence of non-Gaussian noises. The case of robust estimation of states and parameters of linear systems with parameter faults is considered. Because of its good features in robust filtering, the extended Masreliez-Martin filter represents a cornerstone for realization of the robust algorithm. The good features of the proposed robust algorithm to identification of the hydraulic servo cylinder are illustrated by intensive simulations.
\end{abstract}

Key words: robust identification, hydraulic servo cylinder, linear stochastic systems, fault detection, non-Gaussian noises.

\section{Introduction}

$\mathrm{T}$ HE performance of hydraulic systems strongly depends on the control valve and spool geometry and their manufacturing tolerances. Without a proper model, accurate nonlinear analysis of hydraulic system performance is not possible. It is well known that it is very difficult to determine a large number of physical parameters which are an integral part of complex systems. Despite the fact that many system parameters are available with some reasonable accuracy, a large number of parameters are known within a certain range, while some parameters are entirely unknown because manufacturers consider these data as proprietary information. For example, precise determination of system parameters such as dimensions of certain components, leakage coefficients, friction coefficients, as well as static and dynamic friction forces due to impossibility of direct measurement or calculation causes great difficulty in control of servo actuators [1]. More precise knowledge of the system parameters increases the model quality, which causes better control performances. Hence, states filtering as well as parameters estimation can be key factors for performances, stability and accuracy of the systems.

Since Rudolf Kalman published his famous paper [2], the Kalman filter (KF) has become the basis of many estimation processes in different application areas. In recent years, KF has encountered renewed interest, due to an increasing range of applications [3,4]. Precise knowledge of the system parameters and states is crucial for successful realization of many control techniques. Many modern engineering applications such as autonomous vehicles [5], strain prediction for fatigue [6] or robotic manipulation tasks [7] require real-time Kalman filtering framework with linear models.

It is usually too expensive to measure directly the system states. Self-applied state estimation methods assume that the system parameters are constant. In the real world, these parameters always change (e.g. friction coefficients, temperature, pressure, or flow). The states estimation procedure with constant parameters will result in large errors when changing parameters. It is also known that the dynamic behavior of complex systems is usually described by a linear stochastic state space model with time-varying parameters $[8,9]$. Therefore, methods by which parameter and state estimation can be obtained at the same time are required.

A significant number of papers have been published on the theme of the Kalman filter application for parameters estimation of dynamic systems. One of the first papers which deals with this topic is [10]. The convergence analysis of the extended Kalman filter for parameters estimation was analyzed in [11]. Estimation of states and parameters using the Kalman filters is widespread [12-14]. Estimation of states and time-varying parameters is of great practical importance for fault diagnosis and fault tolerant control. One of the biggest challenges in the design of flight control systems is a requirement for the flight of the aircraft to recover safely from structural damage and/or system faults. Regardless of whether the aircraft is equipped with a special control reconfiguration

\footnotetext{
1) Faculty of Mechanical and Civil Engineering in Kraljevo, University of Kragujevac, SERBIA

Correspondence to: Vladimir Stojanović, e-mail: stojanovic.v@mfkv.kg.ac.rs
} 
capability, reliable fault diagnostic information are extremely important to the pilot. The main challenge is the detection and isolation of incipient faults in the presence of modeling uncertainty and noise [15-19]. The problem of joint estimation in dynamic systems has been intensively studied and the basic estimation techniques are well established but, because of the complex nature of dynamic systems, the application of techniques to these problems is not straightforward. These methods are quite popular. Inclusion of unknown parameters in the state vector allows easy implementation of the estimation algorithm, because the problem of parameters estimation in this case is solved using the standard filtering theory. In this way, a good joint estimation technique was obtained. Also, thus derived recursive estimation algorithm enables both offline and online realization.

On the other side, there is no such solution available for linear systems in the presence of non-Gaussian measurements. Because of that, in this paper, it is assumed that the measurement noise is non-Gaussian. Justification of this approach was confirmed in practice [16]. Namely, the known fact is that the measurements have inconsistent observations with the largest part of the observation population (outliers). Their presence can destroy the good features of linearly recursive algorithms which are designed for estimation in the presence of Gaussian noises. Therefore, it is very important to design a robust algorithm which would be a little sensitive to outliers. Huber's theory of robust statistics is crucial for the algorithm design whose robustness is achieved by introducing a nonlinear transformation of prediction error (Huber's function) $[17,18]$

The Masreliez-Martin filter is a frame for realization of the proposed algorithm. It is considered the case when the process noise has a Gaussian distribution, and the measurement noise has a non-Gaussian distribution. Some heuristic modifications have been made in order to improve features of the robust filters. Namely, in a posteriori filter matrix, Fisher information has been replaced with a derivative of Huber's function. The benefits of such modified filters have been shown in [19]. Because of its good properties in robust filtering, the modified extended Masreliez-Martin filter represents a cornerstone for realization of the robust algorithm for state-parameter estimation of linear time-varying stochastic systems in the presence of non-Gaussian noises.

Considering the unknown parameters of the dynamic system, for the purpose of pursuing accuracy robust estimation, this paper proposes two kinds of strategies to estimate the state and parameter jointly. The state estimation and parameter identification are united by the joint parameter and state estimation. It is completely natural to put unknown, generally time-varying, parameters in the vector of states, after which the problem is reduced to the classic filtering problem. This paper considers linear state space systems with parameter faults. In that case, in order to obtain the robust algorithm for estimation of states and parameters, we shall consequently face with a general nonlinear filtering problem. Conventionally, state-parameter robust estimation problem in such systems is based on extended Kalman filter.

The good features of the proposed robust algorithm are illustrated through intensive simulations.

\section{A state space model of the hydraulic servo cylinder}

A schematic view of the hydraulic cylinder with connected four-way spool valve is shown on Fig.1.

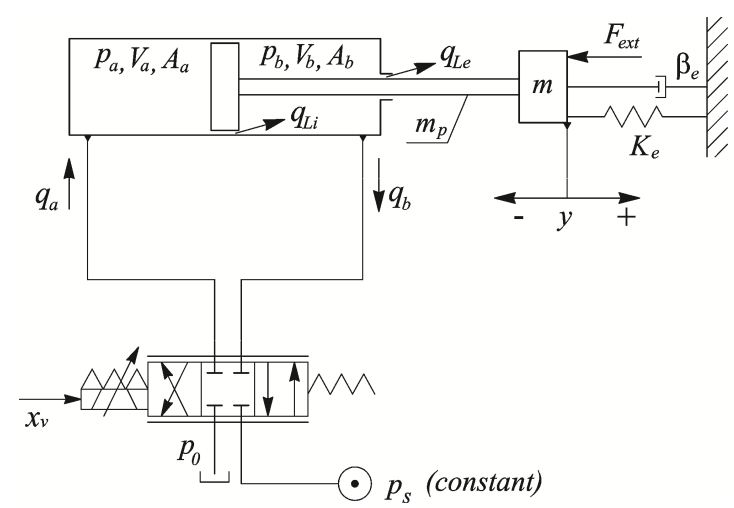

Figure 1. Schematic representation of the valve-controlled asymmetric piston

The load can be seen as summing effects of inertia which comes from the total piston mass $\mathrm{m}_{\mathrm{t}}$, friction forces $\mathrm{F}_{\mathrm{f}}$, spring load forces $\mathrm{K}_{\mathrm{e}} \mathrm{y}$, and disturbance forces $\mathrm{F}_{\text {ext }}$. The spool valve displacement is denoted as $x_{v}$. Pressures $p_{a}$ and $p_{b}$ denote the forward and the return pressure, respectively, the corresponding flows are $q_{a}$ and $q_{b}$, y is the piston displacement, $\mathrm{K}_{\mathrm{e}}$ denotes the load spring gradient, $\mathrm{p}_{\mathrm{S}}$ is the supply pressure, and $\mathrm{p}_{0}$ is the tank pressure. The total mass of the piston $m_{t}$ includes the mass of piston rod $m_{p}$ and the mass of the load $\mathrm{m}$ referred to the piston. The area ratio of the asymmetric piston is $\alpha=A_{b} / A_{a}$, in which $A_{a}$ is the effective area of the head side of the piston, and $A_{b}$ is the effective area of the rod side of the piston, see Fig.1.

Applying the Newton's second law to the forces on the piston, the resulting force equation is:

$$
A_{a} p_{a}-A_{b} p_{b}=m_{t} \ddot{y}+F_{f}(\dot{y})+K_{e} y+F_{e x t}
$$

\section{Pressure dynamics in cylinder chambers}

Applying the continuity equation to each of the cylinder chambers yields:

$$
\begin{gathered}
q_{a}-q_{L i}=\dot{V}_{a}+\frac{V_{a}}{\beta_{e}} \dot{p}_{a} \\
q_{b}+q_{L i}-q_{L e}=\dot{V}_{b}+\frac{V_{b}}{\beta_{e}} \dot{p}_{b}
\end{gathered}
$$

where $\beta_{e}$ is the bulk modulus of the fluid, $q_{L i}$ and $q_{L e}$ denote the internal leakage flow and the external leakage flow, respectively. The internal leakage flow can be calculated by:

$$
q_{L i}=c_{L i}\left(p_{a}-p_{b}\right)
$$

where $c_{L i}$ is the internal leakage flow coefficient. External leakage (leakage from each cylinder chamber to case drain or to tank) is usually neglected, $q_{\text {Lea }}=q_{\text {Leb }}=0$.

The total fluid volumes of two cylinder sides, $\mathrm{V}_{\mathrm{a}}$ and $\mathrm{V}_{\mathrm{b}}$, are given as:

$$
\begin{gathered}
V_{a}=V_{a 0}+y A_{a} \\
V_{b}=V_{b 0}+(L-y) \alpha A_{a}
\end{gathered}
$$


where $\mathrm{L}$ is the piston stroke and $V_{a 0}$ and $V_{b 0}$ represent initial chamber volumes. Equations (2) and (3) can be rearranged to yield the pressure dynamics equations

$$
\begin{aligned}
& \dot{p}_{a}=\frac{\beta_{e}}{V_{a}(y)}\left(q_{a}-A_{a} \dot{y}-q_{L i}-q_{L e a}\right) \\
& \dot{p}_{b}=\frac{\beta_{e}}{V_{b}(y)}\left(q_{b}+\alpha A_{a} \dot{y}+q_{L i}-q_{L e b}\right)
\end{aligned}
$$

\section{Valve flow equations}

The flow through the -th valve orifice $q_{s v i}$ is described by next relation, which takes the direction of the pressure drop into account:

$$
q_{s v i}=q\left(x_{v}, \Delta p\right)=c_{v i} \operatorname{sg}\left(x_{v}\right) \operatorname{sign}(\Delta p) \sqrt{|\Delta p|}
$$

where $i=1,2, \ldots, 4$.

The function $\operatorname{sg}(x)$ is defined by:

$$
\operatorname{sg}(x)= \begin{cases}x, & x \geq 0 \\ 0, & x<0\end{cases}
$$

Discharge coefficients of valve orifices $c_{v i}>0, i=1,2,3,4$ represent valve constants, which will be equal if all orifices are identical. Consider the four-way spool valve as shown in Fig.2.

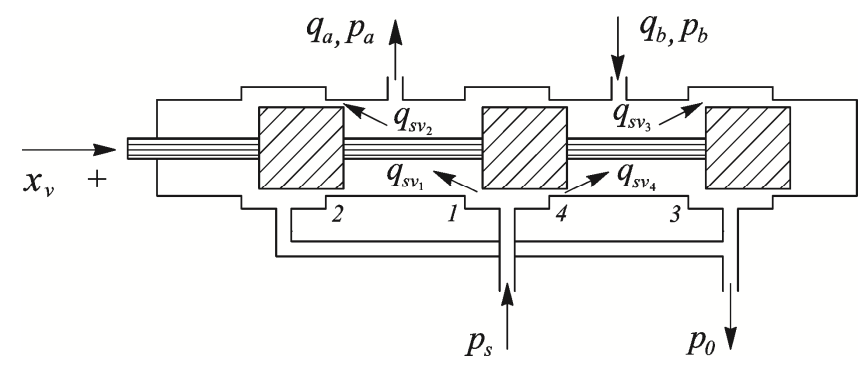

Figure 2. Four-way spool valve

The corresponding flow equations for two valve chambers can be written as:

$$
\begin{aligned}
q_{a}= & q_{s v 1}-q_{s v 2}=c_{v_{1}} \operatorname{sg}\left(x_{v}\right) \operatorname{sign}\left(p_{s}-p_{a}\right) \sqrt{\left|p_{s}-p_{a}\right|}- \\
& -c_{v_{2}} \operatorname{sg}\left(-x_{v}\right) \operatorname{sign}\left(p_{a}-p_{0}\right) \sqrt{\left|p_{a}-p_{0}\right|} \\
q_{b}= & q_{s v 3}-q_{s v 4}=c_{v_{3}} \operatorname{sg}\left(-x_{v}\right) \operatorname{sign}\left(p_{s}-p_{b}\right) \sqrt{\left|p_{s}-p_{b}\right|}- \\
& -c_{v 4} \operatorname{sg}\left(x_{v}\right) \operatorname{sign}\left(p_{b}-p_{0}\right) \sqrt{\left|p_{b}-p_{0}\right|}
\end{aligned}
$$

If state variables and input variables are defined as

$$
\begin{gathered}
X=\left[\begin{array}{llll}
x_{1} & x_{2} & x_{3} & x_{4}
\end{array}\right]^{T} \square\left[\begin{array}{llll}
y & \dot{y} & p_{a} & p_{b}
\end{array}\right]^{T} \\
U=\left[\begin{array}{ll}
u_{1} & u_{2}
\end{array}\right]^{T} \square\left[\begin{array}{ll}
x_{v} & F_{\text {ext }}
\end{array}\right]^{T}
\end{gathered}
$$

then a completely nonlinear model of the hydraulic system, can be expressed in a state-space form as:

$$
\begin{aligned}
\dot{x}_{1} & =x_{2} \\
\dot{x}_{2} & =\frac{1}{m_{t}}\left(A_{a} x_{3}-\alpha A_{a} x_{4}-F_{f}\left(x_{2}\right)-K_{e} x_{1}-u_{2}\right), \\
\dot{x}_{3} & =\frac{\beta_{e}}{A_{a} x_{1}+V_{a 0}}\left(c_{v 1} \operatorname{sg}\left(u_{1}\right) \operatorname{sign}\left(p_{s}-x_{3}\right) \sqrt{\left|p_{s}-x_{3}\right|}-\right. \\
& \left.-c_{v_{4}} \operatorname{sg}\left(-u_{1}\right) \operatorname{sign}\left(x_{3}-p_{0}\right) \sqrt{\left|x_{3}-p_{0}\right|}-\right) \\
& -A_{a} x_{2}-c_{L i}\left(x_{3}-x_{4}\right) \\
\dot{x}_{4} & =\frac{\beta_{e}}{\alpha A_{a}\left(L-x_{1}\right)+V_{b 0}}\left(c_{v_{3}} \operatorname{sg}\left(-u_{1}\right) \operatorname{sign}\left(p_{s}-x_{4}\right)\right. \\
& \sqrt{\left|p_{s}-x_{4}\right|}-c_{v_{2}} \operatorname{sg}\left(u_{1}\right) \operatorname{sign}\left(x_{4}-p_{0}\right) \\
& \left.-\sqrt{\left|x_{4}-p_{0}\right|}+\alpha A_{a} x_{2}+c_{L i}\left(x_{3}-x_{4}\right)\right)
\end{aligned}
$$

It is now more convenient to define the pressure drop across the load, or simply the load:

$$
p_{L}=p_{a}-\alpha p_{b}
$$

which can be seen as the "virtual" pressure required to counterbalance the friction and load forces.

Finally, after linearization of nonlinear equations (15), using previous notation which allows us to present the hydraulic servo system in more compact form, with new state vector $\left[\begin{array}{lll}x_{1} & x_{2} & x_{3}\end{array}\right]^{T} \square\left[\begin{array}{llll}\Delta y(k) & \Delta \dot{y} & \Delta p_{L}\end{array}\right]^{T}$, the discrete time state-space description of the reduced order can be obtained in more compact form, see [20]:

$$
\begin{gathered}
x(k+1)=A(\theta(k)) x(k)+B(\theta(k)) u(k)+w(k) \\
y(k)=x(k)+e(k)
\end{gathered}
$$

where

$$
A(\theta(k))=\left[\begin{array}{ccc}
1 & T_{s} & 0 \\
0 & \frac{T_{m}-T_{s}}{T_{m}} & \frac{T_{s} A_{a}}{m_{p}} \\
0 & -T_{s} K_{d} & \frac{T_{h}-T_{s}}{T_{h}}
\end{array}\right], B(\theta(k))=\left[\begin{array}{cc}
0 & 0 \\
0 & -\frac{T_{s}}{m_{p}} \\
T_{s} K_{Q} & 0
\end{array}\right]
$$

in which $T_{s}=0.01 \mathrm{~s}$ is the known sampling time. The damping of the resonance frequency is determined by the viscous friction $\left(-1 / T_{m}=-B_{C} / m_{p}\right)$ and the leakage $\left(-1 / T_{h}\right)$. Other useful quantities are damping ratio $T_{h}$, the valve control signal term $K_{Q}$, the hydraulic capacitance $C_{h}$, valve flow-pressure coefficients $K_{Q p}$, valve flow gains $K_{Q x}$, as well as pressure sensitivities $K_{p x}=K_{Q x} / K_{Q p}$.

$$
\begin{gathered}
T_{m}=\frac{m_{t}}{B_{C}} \\
K_{Q}=\frac{\beta_{e}}{V_{A}} K_{Q x, A}-\alpha \frac{\beta_{e}}{V_{B}} K_{Q x, B} \\
K_{d}=\frac{A_{1}}{C_{h}}, C_{h}=\left(\frac{\beta_{e}}{V_{A}}+\alpha^{2} \frac{\beta_{e}}{V_{B}}\right)
\end{gathered}
$$




$$
\begin{gathered}
T_{h}=\frac{1}{\alpha \frac{\beta_{e}}{V_{B}}\left[\frac{K_{Q p, B} \alpha^{2}+C_{L i}\left(1+\alpha^{2}\right)}{1+\alpha^{2}}\right] \frac{\beta_{e}}{V_{B}}\left[\frac{K_{Q p, A}-C_{L i}\left(1+\alpha^{2}\right)}{1+\alpha^{2}}\right]} \\
K_{Q p, A}=\left.\frac{\partial Q_{A}}{\partial p_{A}}\right|_{P_{0}}= \begin{cases}\frac{-c_{v} x_{v 0}}{\sqrt{p_{s}-p_{A 0}}} & \text { za } x_{v}>0 \\
\frac{-c_{v} x_{v 0}}{\sqrt{p_{A 0}-p_{0}}} & \text { za } x_{v}<0\end{cases} \\
K_{Q p, B}=\left.\frac{\partial Q_{B}}{\partial p_{B}}\right|_{P_{0}}= \begin{cases}\frac{-c_{v} x_{v 0}}{\sqrt{p_{B 0}-p_{0}}} & \text { za } x_{v}>0 \\
\frac{-c_{v} x_{v 0}}{\sqrt{p_{s}-p_{B 0}}} & \text { za } x_{v}<0\end{cases} \\
K_{Q x, A}=\left.\frac{\partial Q_{A}}{\partial x_{v}}\right|_{P_{0}}= \begin{cases}c_{v} \sqrt{p_{s}-p_{A 0}} & \text { za } x_{v}>0 \\
-c_{v} \sqrt{p_{A 0}-p_{0}} & \text { za } x_{v}<0\end{cases} \\
K_{Q x, B}=\left.\frac{\partial Q_{B}}{\partial x_{v}}\right|_{B_{0}}= \begin{cases}-c_{v} \sqrt{p_{B 0}-p_{0}} & \text { za } x_{v}>0 \\
c_{v} \sqrt{p_{s}-p_{B 0}} & \text { za } x_{v}<0\end{cases}
\end{gathered}
$$

Further, the coefficients $K_{Q p}, K_{Q x}$ and $K_{p x}$ are referred to as valve sensitivity coefficients and are extremely important in determining stability, frequency response, and other dynamic characteristics [20]: the flow gain, $K_{Q x}$, directly affects the open loop gain constant in a system and, therefore, has a direct influence on system stability. The flow-pressure coefficient, $K_{Q p}$, directly affects the damping ratio of valvecylinder combinations. The pressure sensitivity of valves, $K_{p x}$, is quite large, which accounts for the ability of valvecylinder combinations to breakaway large friction loads with little error.

\section{Robust estimation algorithm of linear systems with parameter faults}

In this paper, we consider state-space systems with timevarying parameters in the following form:

$$
\begin{gathered}
x(k+1)=A(\theta(k)) x(k)+B(\theta(k)) u(k)+w(k) \\
y(k)=D(\theta(k)) x(k)+e(k)
\end{gathered}
$$

where $x(k) \in R^{n}$ and $\theta(k) \in R^{p}$ are unknown state and parameter vectors, respectively. From a practical point of view, it is unreasonable to make assumptions about the fault characteristics and not to consider these as unknown time functions. The general form of parameters changing of the stochastic linear system is defined as follows:

$$
\theta(k+1)=G \theta(k)+\eta(k)
$$

in which $G$ is a priori known nonsingular matrix which is convenient for inclusion of a priori information on the phenomenon which is identified. The stochastic process $\eta(k)$ is zero-mean white noise whose covariance matrix $\Phi(k)$ has the form:

$$
\eta(k): N(0, \Phi(k))
$$

Input and measured output vector of the system are $u(k) \in R^{m}$ and $y(k) \in R^{r}$. It is assumed that the process noise is zero-mean Gaussian white noise $w(k): \mathcal{N}(0, Q(k))$, in which $Q(k)$ is the covariance matrix. The measurement noise $e(k)$ has non-Gaussian distribution with approximately normal distribution classes:

$$
\mathscr{P}_{\varepsilon}=\left\{p(e): p(e)=(1-\varepsilon) p_{1}(e)+\varepsilon p_{2}(e)\right\}
$$

in which the probability density $p(e)$ represents a mixture of primary probability density $p_{1}(e): \mathcal{N}\left(0, R_{1}(k)\right)$ and contaminating probability density $p_{2}(e): \mathcal{N}\left(0, R_{2}(k)\right)$ where contamination degree $\varepsilon$ is in range $0<\varepsilon<1$, while $R_{1}(k)$ and $R_{2}(k)$ are covariance matrices of primary and contaminating term in non-Gaussian distribution (23), respectively.

In some cases, the fault $f_{p}(\mathrm{k})$ could be expressed as a change in the system parameter, for example a change in the $i_{\text {th }}$ row and $j_{\text {th }}$ column element of the matrix $A$, the system can then be described as (19-20), see Fig.3.

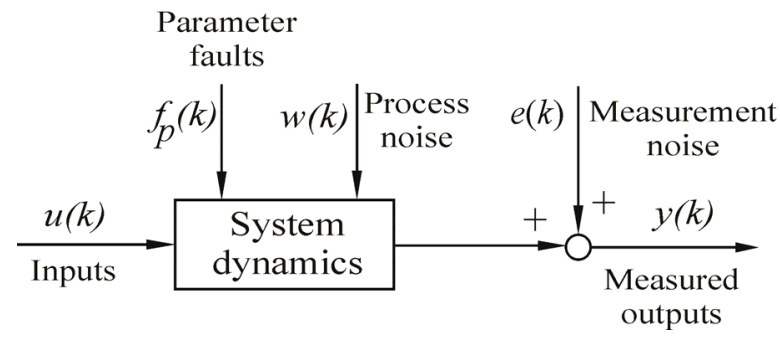

Figure 3. Open-loop system with parameter faults in the system

This approach is based on the assumption that the faults are reflected in the physical system parameters such as friction, mass, viscosity, resistance, inductance, capacitance, etc. As indicated, the linear state space model is often specified up to the value of some parameters $\theta(k)$. Since matrices $A, B$ and $D$ are dependent of parameters $\theta(k)$ and due to multiplying with state vector $x(k)$, the system $(19,20)$ is nonlinear. Hence, to obtain the parameter estimation recursively, we shall consequently face with a general nonlinear filtering problem.

Our goal is to derive the robust algorithm for state and parameter estimation of stochastic linear systems in the presence of outliers which maintains a low sensitivity in appearance of outliers. Using the joint state-parameter formulation, a unified estimation of states and parameters has been achieved. It is completely natural to put the parameters in the vector of states, after which the problem is reduced to the classic filtering problem of $k-t h$ order unified system (where $k=n+p$, in which $n$ is a number of estimated states and $p$ is a number of estimated parameters).

The robust extended Kalman filter can be used to estimate states and parameters of linear stochastic systems, after the joint state-parameter formulation:

$$
z(k)=\left[\begin{array}{c}
f_{k-1}(x(k-1), u(k-1), \theta(k-1)) \\
g_{k-1}(\theta(k-1))
\end{array}\right]+\left[\begin{array}{l}
w(k-1) \\
\eta(k-1)
\end{array}\right]
$$

The extended system is given in a more compact form:

$$
z(k)=q_{k-1}(z(k-1), u(k-1), \theta(k-1))+\xi(k-1)
$$




$$
y(k)=h_{k}(z(k), \theta(k))+e(k)
$$

where $z(k)$ denotes the extended state vector $z(k)=\left[\begin{array}{llll}x^{T}(k) & \theta^{T}(k)\end{array}\right]^{T}, \quad \xi(k-1) \quad$ represents extended disturbance vector $\xi(k-1)=\left[\begin{array}{lll}w^{T}(k-1) & \eta^{T}(k-1)\end{array}\right]^{T}$, in which

$$
\xi(k): N(0, \Xi(k)) \text { and } \Xi(k)=\left[\begin{array}{cc}
Q(k) & 0 \\
0 & \Phi(k)
\end{array}\right] .
$$

Based on extended robust filter which is proposed in [19], the robust algorithm for states-parameters estimation of system $(25,26)$ has the following form:

$$
\begin{aligned}
& \hat{z}(k \mid k-1)=q_{k-1}(\hat{z}(k-1 \mid k-1), u(k-1), \theta(k-1), 0) \\
& P(k \mid k-1)=F(k-1) P(k-1 \mid k-1) F^{T}(k-1)+ \\
& +L(k-1) \Xi(k-1) L^{T}(k-1) \\
& K(k)=P^{T}(k \mid k-1) H^{T}(k) T^{T}(k) \\
& v(k)=T(k)\left[y(k)-h_{k}(\hat{z}(k \mid k-1), \theta(k), 0)\right] \\
& \hat{z}(k \mid k)=\hat{z}(k \mid k-1)+K(k) \Psi(v(k)) \\
& P(k \mid k)=P(k \mid k-1)-K(k) \Psi^{\prime}(v(k)) K^{T}(k) \\
& \Psi^{\prime}(v(k))=\left[\begin{array}{ccc}
\psi^{\prime}\left(v_{1}(k)\right) & \ldots & 0 \\
0 & \ddots & 0 \\
0 & \ldots & \psi^{\prime}\left(v_{r}(k)\right)
\end{array}\right]
\end{aligned}
$$

$$
T(k)=\left[H(k) P(k \mid k-1) H^{T}(k)+V(k) R_{1}(k) V^{T}(k)\right]^{-\frac{1}{2}}
$$

where

$$
\begin{aligned}
F(k) & =\left.\frac{\partial q_{k}}{\partial z}\right|_{\hat{z}(k \mid k)}=\left[\begin{array}{c:c}
A(k) & F_{\theta}(k) \\
\hdashline 0 & I_{p}
\end{array}\right] ; L(k)=\left.\frac{\partial q_{k}}{\partial \xi}\right|_{\hat{z}(k \mid k)}= \\
& =I_{n+p} \\
H(k) & =\left.\frac{\partial h_{k}}{\partial z}\right|_{\hat{z}(k \mid k-1)}=\left[D(k) H_{\theta}(k)\right] ; V(k)= \\
& =\left.\frac{\partial h_{k}}{\partial v}\right|_{\hat{z}(k \mid k-1)}=I_{r}
\end{aligned}
$$

Initial conditions are: $\hat{z}_{0}=0$ and $P_{0}=\left[\begin{array}{c:c}P\left(x_{0}\right) & 0 \\ \hdashline 0 & \bar{P}\left(\bar{\theta}_{0}\right)\end{array}\right]$.

Here $\hat{z}(k)$ is the estimate of extended state vector, and generally, $P(k)$ denotes the filter covariance matrix $P(k)=E\left\{(\hat{x}(k)-x(k))(\hat{x}(k)-x(k))^{T}\right\}$. In relation (31), $v(k)$ represents transformed residuals $\varepsilon(k)=$ $=y(k)-H(k) \hat{z}(k-1 \mid k-1)$. In order to fulfill the conditions of symmetry of certain probability densities and conditions for marginal probabilities, the transformation $T(k)$ has been included in the residual [18].

For the class of $\varepsilon$-contaminated distributions of probabilities, the nonlinear transformation of prediction error $\psi(\cdot)$ (Huber's function), is obtained using game theory in statistics [17]

$$
\psi(v(k))=\min \left\{\left|v(k), k_{\varepsilon}\right|\right\} \operatorname{sgn}(v(k))
$$

and its derivative:

$$
\psi^{\prime}(v(k))=\left\{\begin{array}{lc}
1 & |v(k)|<k_{\varepsilon} \\
0 & \text { otherwise }
\end{array}\right.
$$

in which $k_{\varepsilon}$ is an appropriately defined parameter of Huber's function, see Fig.4.

The following relation determines the relationship between the contamination degree $\varepsilon$ and the parameter $k_{\varepsilon}$ of Huber's function [17]:

$$
\begin{aligned}
& \frac{\Phi_{N}^{\prime}\left(k_{\varepsilon}\right)}{k_{\varepsilon}}-2 \Phi_{N}\left(-k_{\varepsilon}\right)=\frac{\varepsilon}{1-\varepsilon}, \\
& \Phi_{N}(x)=\frac{1}{\sqrt{2 \pi}} \int_{-\infty}^{x} e^{-\frac{y^{2}}{2}} d y
\end{aligned}
$$

in which $\Phi_{N}$ represents the standard normal cumulative distribution function.

a)

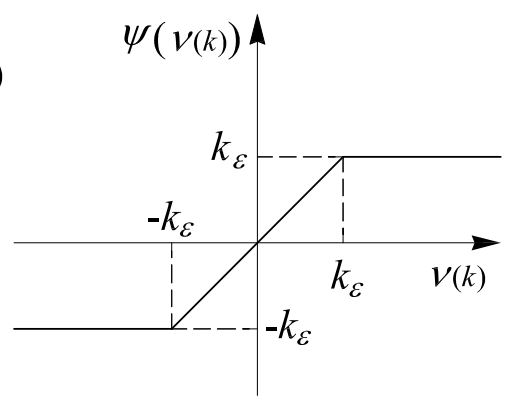

b)

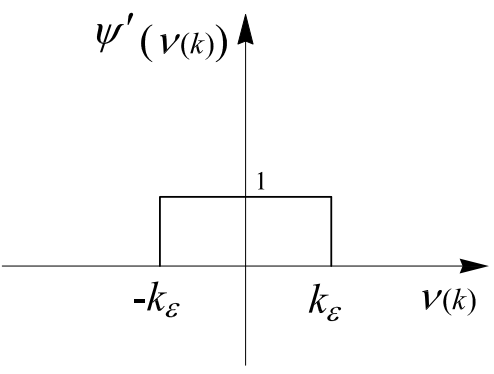

Figure 4. Huber's function and its derivative

It can be shown that the mathematical expectation and the covariance matrix of transformed residuals $\varepsilon(\mathrm{k})=y(k)-H(k) \hat{x}(k-1 \mid k-1)$ are:

$$
\begin{gathered}
E\{v(k)\}=T(k) E\{\varepsilon(k)\}=0 \\
E\left\{v^{2}(k)\right\}=T^{2}(k)\left[H(k) P(\mathrm{k} \mid k-1) H^{T}(k)+R_{1}(\mathrm{k})\right]^{-\frac{1}{2}}
\end{gathered}
$$

Therefore, in case that transformation $T(k)$ is:

$$
T(k)=\left[H(k) P(\mathrm{k} \mid k-1) H^{T}(k)+R_{1}(\mathrm{k})\right]^{-1 / 2}
$$

the covariance matrix of the transformed residuals will be $I$.

The following block structure of the matrix gain and covariance matrices is in accordance with the joint stateparameter formulation (24): 


$$
\begin{aligned}
& K(k)=\left[\frac{N(k)}{\bar{M}(k)}\right] \\
& P(k \mid k-1)=\left[\begin{array}{c:c}
P_{1}(k \mid k-1) & P_{2}(k \mid k-1) \\
\hdashline P_{2}^{T}(k \mid k-1) & P_{3}(k \mid k-1)
\end{array}\right]
\end{aligned}
$$

and

$$
P(k \mid k)=\left[\begin{array}{c:c}
P_{1}(k \mid k) & P_{2}(k \mid k) \\
\hdashline P_{2}^{T}(k \mid k) & P_{3}(k \mid k)
\end{array}\right]
$$

Keeping this in mind, estimates of a priori and a posteriori extended state vectors, relations (28) and (32), are given by the following relations:

$$
\begin{gathered}
\hat{z}(k \mid k-1)=\left[\begin{array}{c}
f_{k-1}(\hat{x}(k-1 \mid k-1), u(k-1), \hat{\theta}(k-1 \mid k-1)) \\
\hat{\theta}(k-1 \mid k-1)
\end{array}\right] \\
\hat{z}(k \mid k)=\left[\begin{array}{c}
\hat{x}(k \mid k-1) \\
\hat{\theta}(k \mid k-1)
\end{array}\right]+\left[\begin{array}{c}
N(k) \\
M(k)
\end{array}\right][\Psi(v(k))]
\end{gathered}
$$

Now, it is easy to express the estimates of the state and parameter vectors:

$$
\begin{aligned}
& \hat{x}(k \mid k)=f_{k-1}(\hat{x}(k-1 \mid k-1), u(k-1), \hat{\theta}(k-1 \mid k-1))+ \\
& +N(k) \Psi(v(k)) \\
& \hat{\theta}(k \mid k)=\hat{\theta}(k-1 \mid k-1)+M(k) \Psi(v(k))
\end{aligned}
$$

In this way, the robust algorithm for the states-parameters estimation of linear stochastic systems with parameter faults, has been derived.

\section{Simulation results}

Determination of exact state and parameter values of the valve-controlled hydraulic cylinder is a basic prerequisite for a high-quality synthesis of control algorithms and an adequate choice of controller parameters. This causes energy savings in processes of production, transportation, and energy consumption, and in special, in energy and working machines.

Adopted sampling time is $T_{s}=0.01 \mathrm{~s}$. The model parameters are: $\beta_{e}=2.1 \cdot 10^{8} \mathrm{~Pa}$ is the bulk modulus of the fluid, $K_{e}=10^{-1}$ denotes the load spring gradient, $F_{\text {ext }}$ represents the load force disturbance on the piston, $p_{S}=40 \mathrm{bar}$ is the supply pressure, and $p_{0}=1.7 \mathrm{bar}$ is the tank pressure, $V_{a 0}=V_{b 0}=8 \cdot 10^{-6} \mathrm{~m}^{3}$ represent initial chamber volumes, $L=1 m$ is the piston stroke, $m=20 \mathrm{~kg}$ is the piston mass. The area ratio of the asymmetric piston is $\alpha=A_{b} / A_{a}$, where $A_{b}=2.36 \cdot 10^{-4} \mathrm{~m}^{2}$ is the effective area of the head side of the piston, and $A_{a}=4.91 \cdot 10^{-4} \mathrm{~m}^{2}$ is the effective area of the rod side of the piston. Discharge coefficients of valve orifices $c_{v i}>1.14, i=1,2,3,4$ represent valve constants, and $c_{L i}=5 \cdot 10^{-14}$ is the internal leakage coefficient. The term $F_{f}\left(x_{2}\right)$ in equation (17) describes the summing nonlinear effects of viscous, static and Coulomb friction forces of the system.

$$
F_{f}\left(x_{2}\right)=B_{c} x_{2}+\operatorname{sign}\left(x_{2}\right)\left[F_{c 0}+F_{s 0} e^{-\frac{\left|x_{2}\right|}{c_{s}}}\right]
$$

in which $B_{C}=220 \mathrm{Ns} / \mathrm{m}$ is the parameter for viscous friction, $F_{c 0}=50 \mathrm{~N}$ is the parameter for Coulomb friction, and $F_{s 0}=30 \mathrm{~N}$ and $c_{s}=0.015 \mathrm{~m} / \mathrm{s}$ are parameters for static friction. The detailed analysis for the influences of friction forces can be found in [20].

Since the linear state space system with parameter faults is considered, we need to apply the extended Kalman filter based algorithm. Following results demonstrate superiority of the proposed robust estimation algorithm in the presence of non-Gaussian noises in relation to the estimation algorithms based on widely-used extended Kalman filter and extended Masreliez-Martin filter. Behavior of the algorithm will be considered on:

$$
\begin{gathered}
{\left[\begin{array}{l}
x_{1}(k+1) \\
x_{2}(k+1) \\
x_{3}(k+1)
\end{array}\right]=\left[\begin{array}{ccc}
1 & 0.01 & 0 \\
0 & p_{1} & 2.4 \cdot 10^{-7} \\
0 & p_{2} & p_{3}
\end{array}\right]\left[\begin{array}{l}
x_{1}(k) \\
x_{2}(k) \\
x_{3}(k)
\end{array}\right]+} \\
+\left[\begin{array}{cc}
0 & 0 \\
0 & -5 \cdot 10^{-4} \\
p_{4} & 0
\end{array}\right]\left[\begin{array}{l}
u_{1}(k) \\
u_{2}(k)
\end{array}\right]+\left[\begin{array}{l}
w_{1}(k) \\
w_{2}(k) \\
w_{3}(k)
\end{array}\right] \\
{\left[\begin{array}{l}
y_{1}(k) \\
y_{2}(k)
\end{array}\right]=\left[\begin{array}{l}
x_{1}(k) \\
x_{2}(k)
\end{array}\right]+\left[\begin{array}{l}
e_{1}(k) \\
e_{2}(k)
\end{array}\right]}
\end{gathered}
$$

The features of the proposed robust algorithm are considered on the model whose time-varying parameter vector has expected value:

$$
\bar{\theta}=\left[\begin{array}{llll}
0.88 & -0.87 & 1.79 & 1.21
\end{array}\right]^{T}
$$

The process noise $w(k)$ is zero-mean white noise with covariance matrix:

$$
Q(\mathrm{k})=\left[\begin{array}{ccc}
10^{-5} & 0 & 0 \\
0 & 3 \cdot 10^{-4} & 0 \\
0 & 0 & 2 \cdot 10^{-3}
\end{array}\right]
$$

The covariance matrix of parameters has the form:

$$
\Phi(k)=\left[\begin{array}{cccc}
2 \cdot 10^{-6} & 0 & 0 & 0 \\
0 & 1 \cdot 10^{-5} & 0 & 0 \\
0 & 0 & 2 \cdot 10^{-6} & 0 \\
0 & 0 & 0 & 3 \cdot 10^{-4}
\end{array}\right]
$$

The non-Gaussian distribution of the measured noise is given by

$\mathscr{P}_{\varepsilon}=\left\{\begin{array}{l}p\left(v_{1}\right)=\left(1-\varepsilon_{1}\right) \cdot \mathcal{N}(0 ; 0.0001)+\varepsilon_{1} \cdot \mathcal{N}(0 ; 0.01), \\ p\left(v_{2}\right)=\left(1-\varepsilon_{2}\right) \cdot \mathcal{N}(0 ; 0.0001)+\varepsilon_{2} \cdot \mathcal{N}(0 ; 0.01)\end{array}\right\}$

For the purpose of illustrating estimation quality, mean square error (MSE) is used as follows:

$$
M S E=\ln \left(\mathrm{E}\|\hat{z}(k)-z(k)\|^{2}\right)
$$

The system outputs, estimates of states and parameters, as well as mean square errors in case when contaminations have values $\varepsilon_{1}=\varepsilon_{2}=0.15$ are shown in Figures 5-8. 


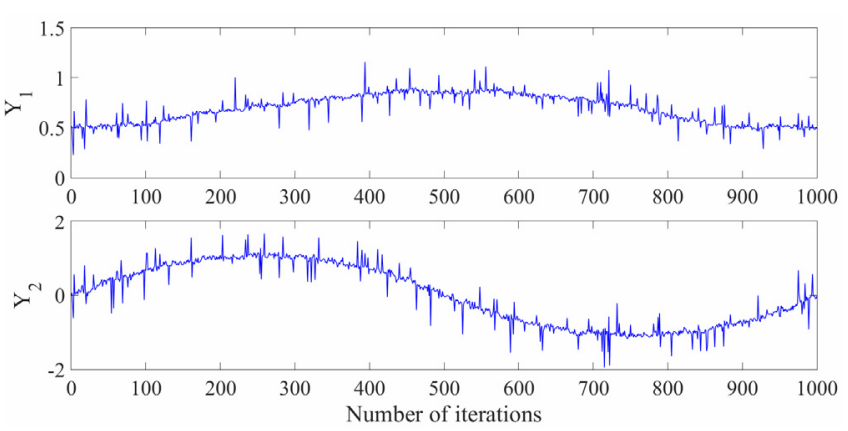

Figure 5. System output signals

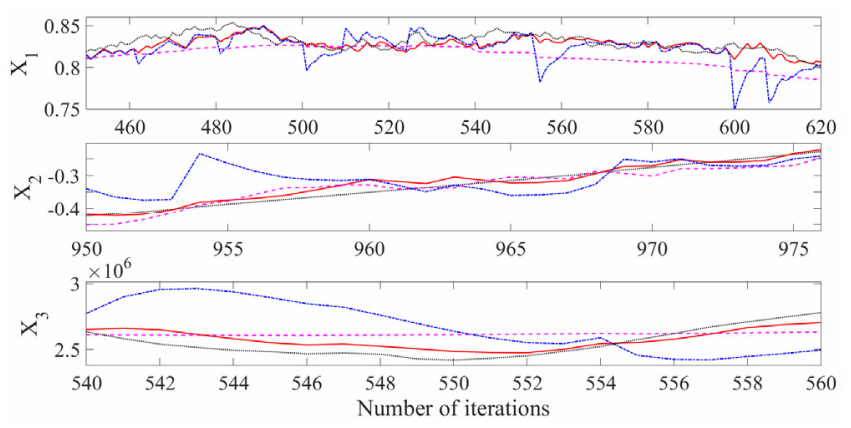

Figure 6. States estimates (solid line: Proposed robust algorithm, dashed line: Algorithm based on extended Masreliez-Martin filter, dash-dot: Algorithm based on extended Kalman filter, dotted line: True values of states).

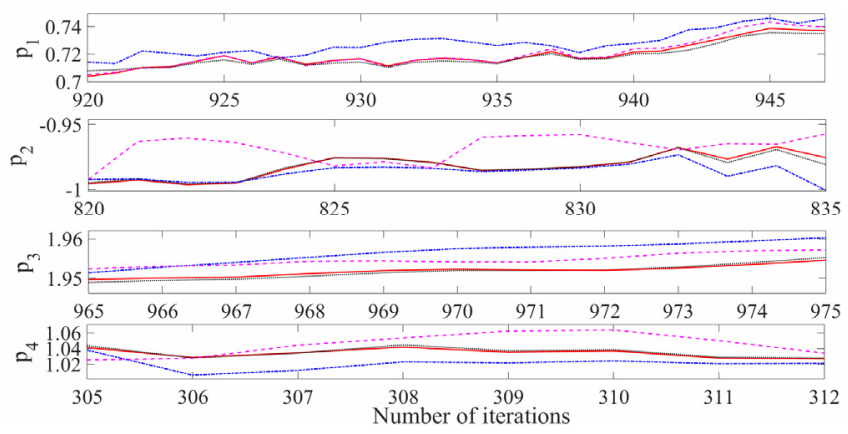

Figure 7. Parameters estimates (solid line: Proposed robust algorithm, dashed line: Algorithm based on extended Masreliez-Martin filter, dash-dot: Algorithm based on extended Kalman filter, dotted line: True values of states).

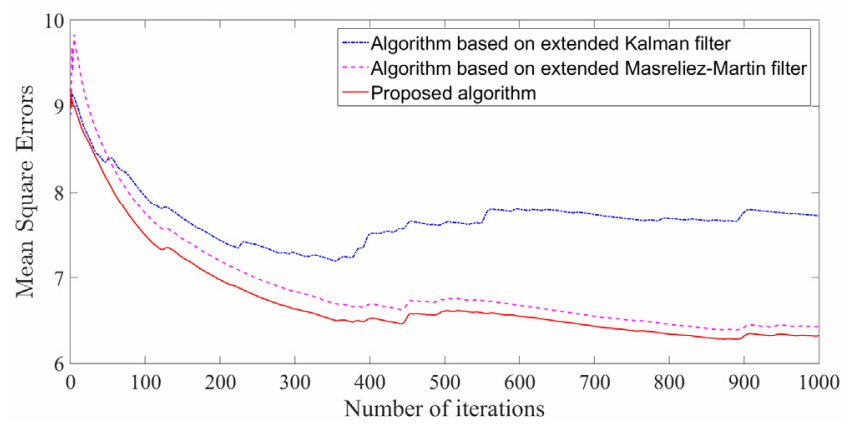

Figure 8. Mean square errors

The presented results have shown that the widely-used extended Kalman filter (EKF) is very sensitive to the presence of non-Gaussian noises, as opposed to the proposed robust estimation algorithm. In order to show robustness of the proposed robust estimation algorithm for systems with parameter faults in relation to other conventional and widelyused estimation algorithms as well as some modern filters, the algorithms are run 50 times independently, for different contamination degrees. Furthermore, it is particularly important to note that the proposed robust estimation algorithm for systems with parameter faults (REA) keeps high performances in relation to joint estimation algorithms based on modern filters such as particle filter (PF). Table 1 provides statistical data based on 1000 iterations.

Table 1. Mean square errors for different degrees of contaminations.

\begin{tabular}{|c|c||c||c||c||}
\hline Estimation algorithms & Mean & Best & Worst & Variance \\
\hline \hline Case I & \multicolumn{3}{|c||}{ Contamination degree $\varepsilon=0.05$} \\
\hline \hline EKF & -1.4246 & -1.6615 & -1.0493 & 0.0110 \\
\hline \hline PF & -2.3275 & -2.6391 & -2.1653 & 0.0112 \\
\hline \hline EMMF & -2.8431 & -3.0315 & -2.5911 & 0.0095 \\
\hline \hline REA & -4.2473 & -4.4349 & -3.9921 & 0.0077 \\
\hline \hline Case II & \multicolumn{3}{|c||}{ Contamination degree $\varepsilon=0.1$} \\
\hline \hline EKF & -0.8371 & -1.0913 & -0.5615 & 0.0119 \\
\hline \hline PF & -1.3791 & -1.7025 & -1.1411 & 0.0114 \\
\hline \hline EMMF & -2.6544 & -2.9043 & -2.5288 & 0.0101 \\
\hline \hline REA & -3.8731 & -4.1006 & -3.6747 & 0.0083 \\
\hline \hline Case III & \multicolumn{3}{|c||}{ Contamination degree $\varepsilon=0.2$} \\
\hline \hline EKF & -0.7171 & -0.9256 & -0.4417 & 0.0129 \\
\hline \hline PF & -1.0461 & -1.2856 & -0.8474 & 0.0120 \\
\hline \hline EMMF & -2.4136 & -2.6036 & -2.1280 & 0.0105 \\
\hline \hline REA & -3.2892 & -3.5101 & -3.0779 & 0.0090 \\
\hline
\end{tabular}

From Table 1, it can be seen that the worst results obtained by the proposed robust algorithm is even better than the best result obtained by others, at a certain contamination degree. Furthermore, from Table 1, it can be clearly seen that the superiority of the proposed robust algorithm is greater in higher degrees of contamination.

\section{Conclusions}

An application of the proposed robust algorithm to identification of hydraulic servo cylinders is considered. Namely, due to impossibility of direct measurement or calculation of dimensions of certain components, leakage coefficients or friction coefficients, it was supposed that parameters of the hydraulic servo system are stochastic. Change of parameters of the model was described by random walk. Because nonlinear models can be approximated by a linear model with time-varying parameters, the nonlinear model of the hydraulic cylinder was approximated with timevarying linear model. For this purpose, the state and parameter robust estimation algorithm in presence of nonGaussian noises has been proposed. Since the system is described with a stochastic model with variable parameters, robust Kalman filters were the natural frame for identification. Because of their good features in robust filtering, the modified extended Masreliez-Martin filter was used as a basis in formulating the joint robust estimator of linear stochastic systems. The benefits of the proposed robust algorithm were illustrated through intensive simulations.

\section{Acknowledgements}

This research has been supported by the Serbian Ministry of Education, Science and Technological Development through projects TR33026 and TR33027.

\section{References}

[1] FILIPOVIC,V., NEDIC,N., STOJANOVIC,V.: Robust identification of pneumatic servo actuators in the real situations, Forschung im Ingenieurwesen - Engineering Research, 2011, Vol.75, No.4, pp.183196. 
[2] KALMAN,R.E.: New Approach to Linear Filtering and Prediction Problems, Transactions of the ASME - Journal of Basic Engineering, 1960, Vol.82, No.1, pp.35-45.

[3] CHANG,Y.H., HU,Q., TOMLIN,C.J.: Secure estimation based Kalman Filter for cyber-physical systems against sensor attacks, Automatica, 2018, Vol.95, pp.399-412.

[4] CHANG,L., ZHA,F., QIN,F.: Indirect Kalman Filtering Based Attitude Estimation for Low-Cost Attitude and Heading Reference Systems, IEEE/ASME Transactions on Mechatronics, 2017, Vol.22, No.4, pp. $1850-1858$.

[5] VIEGAS,D., BATISTA,P., OLIVEIRA,P., SILVESTRE,C.: Discretetime distributed Kalman filter design for formations of autonomous vehicles, Control Engineering Practice, 2018, Vol.75, pp.55-68.

[6] MAES,K., ILIOPOULOS,A., WEIJTJENS,W. DEVRIENDT,C., LOMBAERT,G.: Dynamic strain estimation for fatigue assessment of an offshore monopile wind turbine using filtering and modal expansion algorithms, Mechanical Systems and Signal Processing, 2016, Vol.7677, pp.592-611.

[7] CAVAllO,A., DE MARIA,G., NATAlE,C., PIROZZI,S.: Slipping detection and avoidance based on Kalman filter, Mechatronics, 2014, Vol.24, No.5, pp.489-499.

[8] STOJANOVIC,V., NEDIC,N.: Identification of time-varying OE models in presence of non-Gaussian noise: Application to pneumatic servo drives, International Journal of Robust and Nonlinear Control, 2016, Vol. 26, No. 18, pp. 3974-3995.

[9] RODRIGUEZ, M.T., BANKS, S.P., Linear, Time-varying Approximations to Nonlinear Dynamical Systems, Springer, Berlin, 2010.

[10] COX,H., On the estimation of state variables and parameters for noisy dynamic systems, IEEE Transactions on Automatic Control, 1964, Vol.9, No.1, pp.5-12.

[11] LJUNG,L.: Asymptotic behavior of the extended Kalman filter as a parameter estimator for linear systems, IEEE Transactions on Automatic Control, 1979, Vol.24, No.1, pp.36-50.

[12] AKSOY,S. MUHURCU,A., KIZMAZ,H.: State and parameter estimation in induction motor using the Extended Kalman Filtering algorithm, Proceedings of the International Symposium Modern Electric Power Systems, Wroclaw, Poland, September 2010, pp.1-5.
[13] PLETT,G.L.: Extended Kalman filtering for battery management systems of LiPB-based HEV battery packs: Part 3. State and parameter estimation, Journal of Power Sources, 2004, Vol.134, No.2, pp.277292.

[14] CARRASSI,A., VANNITSEM,S.: State and parameter estimation with the extended Kalman filter: an alternative formulation of the model error dynamics, Quarterly Journal of the Royal Meteorological Society, 2011, Vol.137, No.655, pp.435-451.

[15] ISERMANN,R.: Fault-Diagnosis Applications: Model-Based Condition Monitoring: Actuators, Drives, Machinery, Plants, Sensors, and Fault-tolerant Systems, Springer, 2011.

[16] CHIANG,L.H., RUSSELL,E.L., BRAATZ,R.D.: Fault Detection and Diagnosis in Industrial Systems, Springer, 2001.

[17] DING,S.X.: Model-Based Fault Diagnosis Techniques: Design Schemes, Algorithms and Tools, Springer, 2012.

[18] JELALI,M: Control Performance Management in Industrial Automation: Assessment, Diagnosis and Improvement of Control Loop Performance, Springer, 2013.

[19] KHAN,R., WILLIAMS,P., RISEBOROGH,P., RAO,A., HILL,R.: Fault detection and identification-A filter investigation, International Journal of Robust and Nonlinear Control, 2018, Vol.28, No.5, pp.18521870 .

[20] BARNET,V., LEWIS,T.: Outliers in statistical data, 3rd ed. WileyBlackwell, New York, 1994.

[21] HUBERP.J.: Robust statistics, Wiley, New York, 1981.

[22] MASRELIEZ,C.J., MARTIN,R.D.: Robust Bayesian estimation for the linear model and robustifying the Kalman filter, IEEE Transactions on Automatic Control, 1977, Vol.22, No.3, pp.361-371.

[23] STOJANOVIC,V., NEDIC,N.: Robust Kalman filtering for nonlinear multivariable stochastic systems in the presence of non-Gaussian noise, International Journal of Robust and Nonlinear Control, 2016, Vol.26, No.3, pp.445-460.

[24] JELALI,M., KROLL,A.: Hydraulic Servo-systems: Modelling, Identification and Control, Springer, 2003.

\title{
Robusna identifikacija za detekciju otkaza i dijagnostiku hidrauličkog servo cilindra
}

\begin{abstract}
Intenzivna istraživanja u oblasti matematičkog modelovanja hidrauličnih servo sistema pokazala su da njihovi matematički modeli imaju mnogo bitnih detalja koji se ne mogu uključiti u model. Zbog nemogućnosti direktnog merenja ili izračunavanja dimenzija pojedinih komponenti, koeficijenata curenja ili koeficijenta trenja, pretpostavlja se da su parametri hidrauličnog servo sistema slučajni (stohastičke prirode). Sa druge strane, dobro je poznato da se hidraulični servo cilindar može aproksimirati linearnim modelom sa vremenski promenljivim parametrima. Procena stanja i vremenski promenljivih parametara linearnih sistema u prostoru stanja je od velike važnosti za detekciju i dijangnostiku kao i za upravljanje koje je tolerantno na otkaze. Prethodni radovi na ovu temu razmatraju zajedničku procenu u okruženju Gausovih šumova, ali ne i u prisustvu autlajera. Poznata je činjenica da merenja sadrže nekonzistentne opservacije u odnosu na glavninu populacije opservacija (autlajeri). Oni mogu značajno pokvariti svojstva linearnih rekurzivnih algoritama koji su projektovani da rade u prisustvu Gaussovih šumova. U ovom radu je predložena strategija zajedničke robusne procene parametara i stanja linearnih modela u prostoru stanja u prisustvu negausovih šumova. Razmatran je slučaj robusne procene stanja i parametara linearnih sistema sa greškama parametara. Zbog svojih dobrih karakteristika u robusnoj filtraciji, prošireni Masreljez-Martinov filtar predstavlja osnovu za realizaciju robusnog algoritma. Dobre osobine predloženog robusnog algoritma za identifikaciju hidrauličnog servo cilindra ilustrovane su uz pomoć intenzivnih simulacija.
\end{abstract}

